\title{
Elastic Diffraction and Non-Perturbative Gluons
}

\author{
L.Jenkovszky ${ }^{(1)}$, A.Kotikov $^{(2)}$, F.Paccanoni $^{(3)}$
}

1) Institute for Theoretical Physics, Kiev, Ukraine

2) Joint Institute for Nuclear Research, Dubna, Russia

3) Dip. di Fisica, Padova - INFN Sezione di Padova, Italy

\begin{abstract}
We consider a simple model for the propagator of a non-perturbative gluon and derive the rules determining its coupling to perturbative gluons and quarks. With these rules, we evaluate the fourth and sixth-order amplitude for quark-quark scattering at high energies.

In this framework, numerical predictions are presented for high energy nucleonnucleon scattering and compared with experimental data.
\end{abstract}




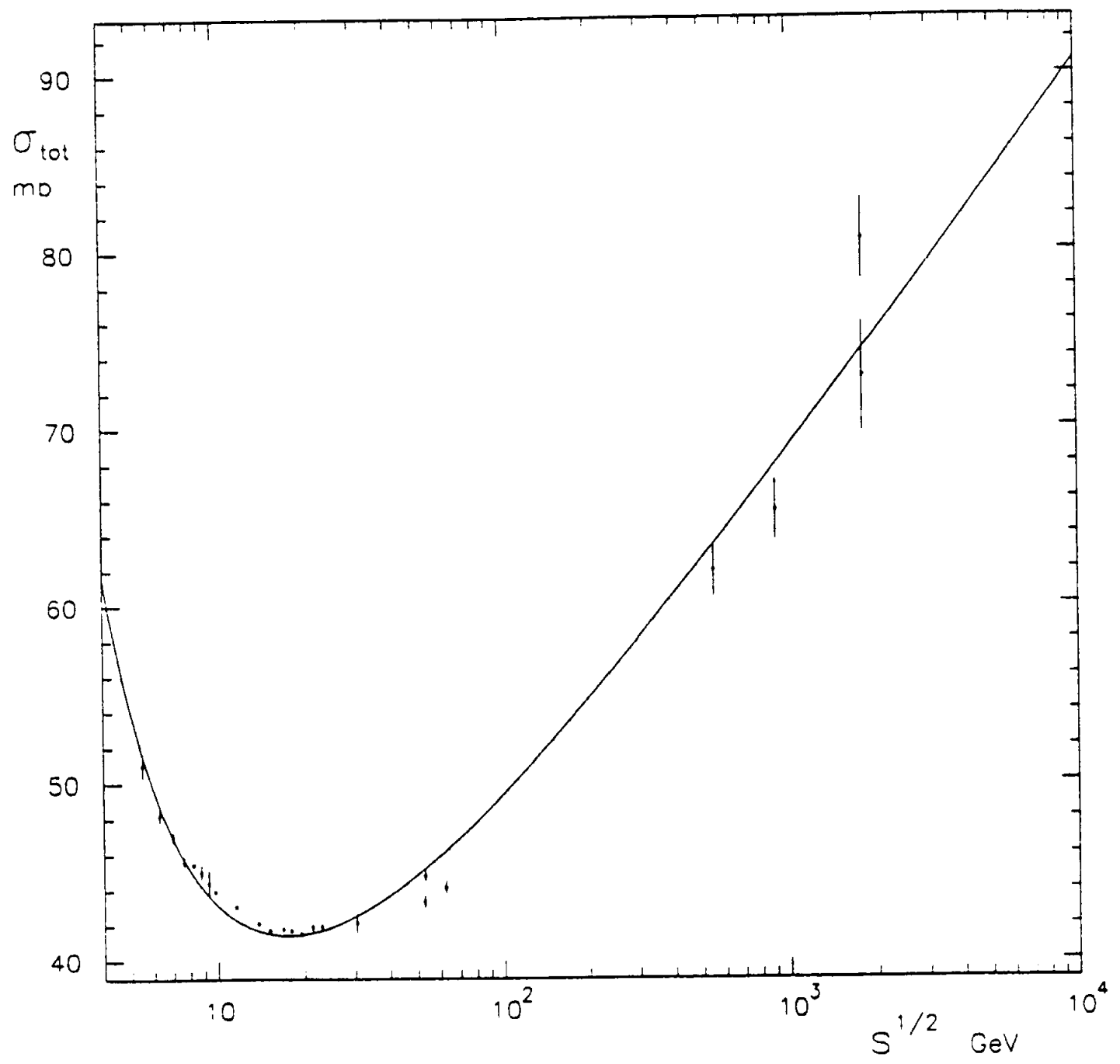

Fig. 2 


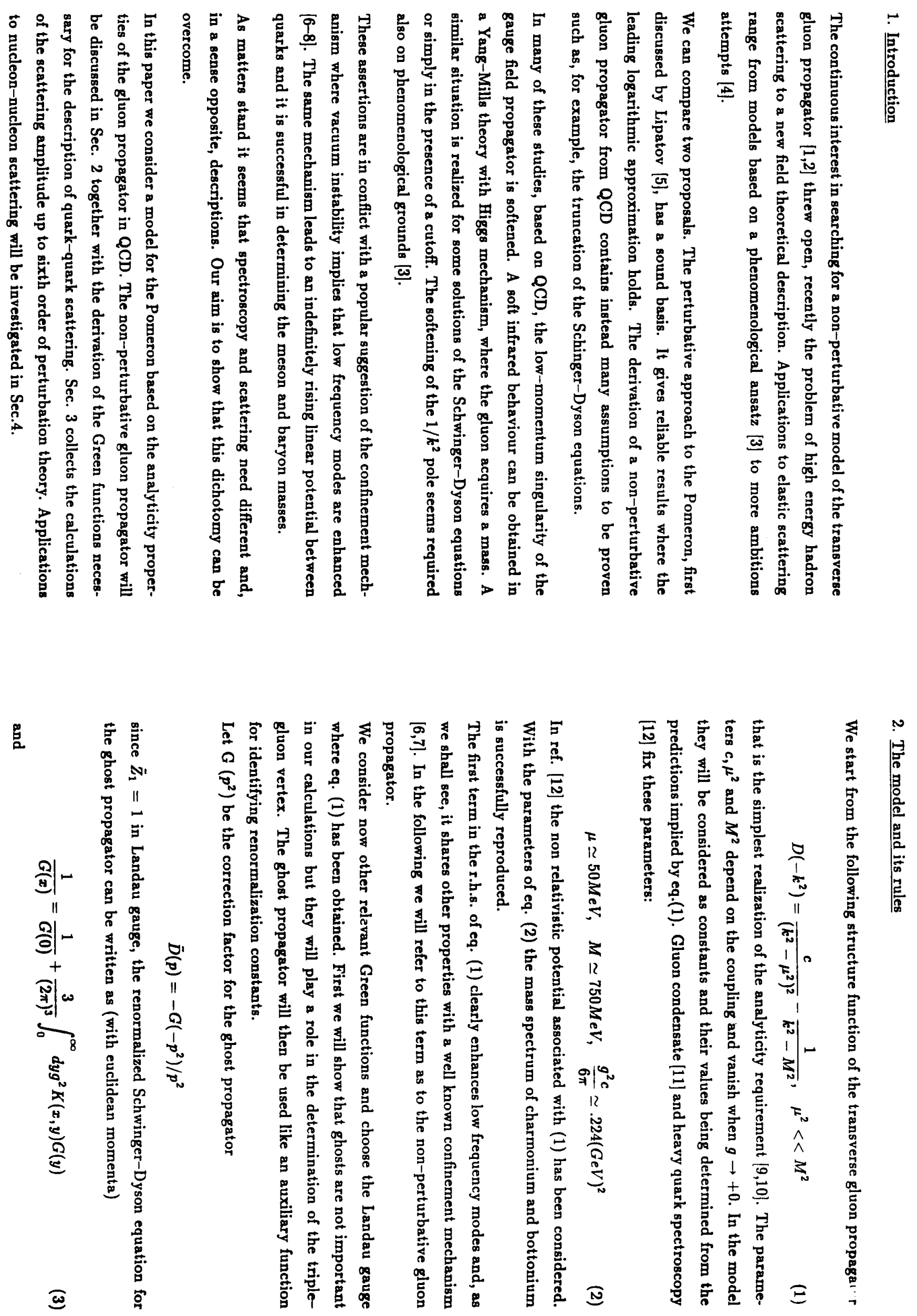


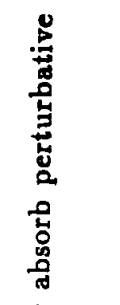

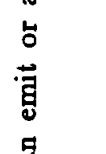

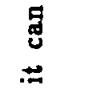

II

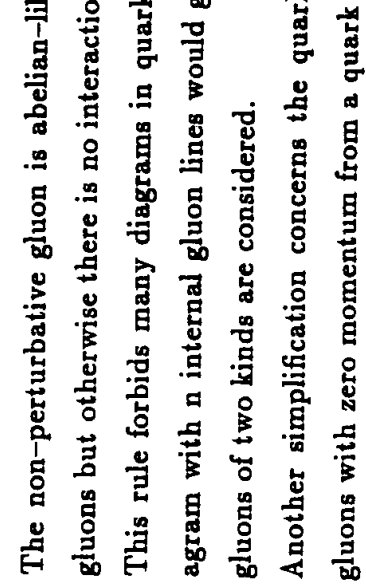

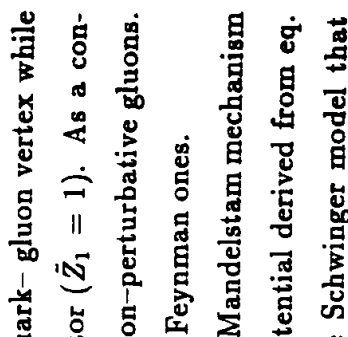

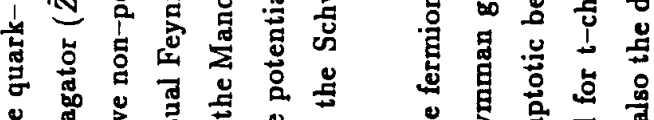

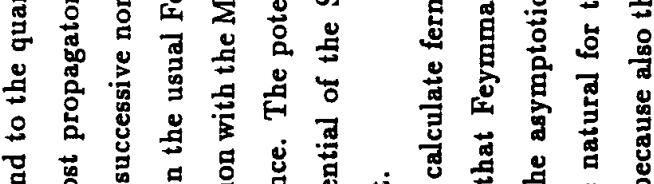

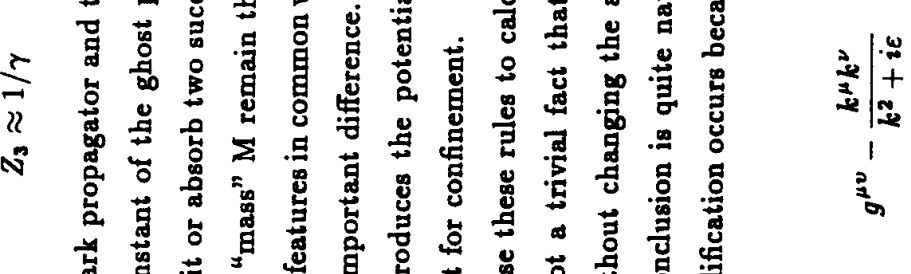

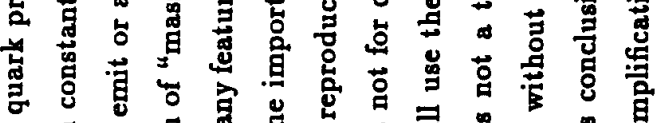

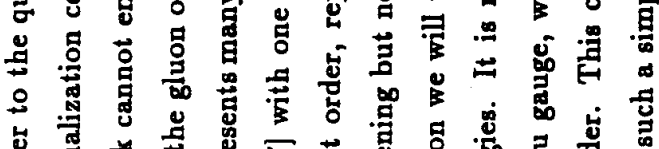

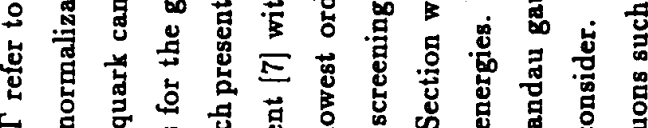

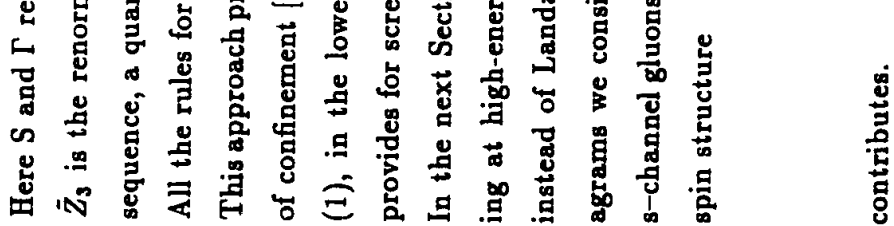

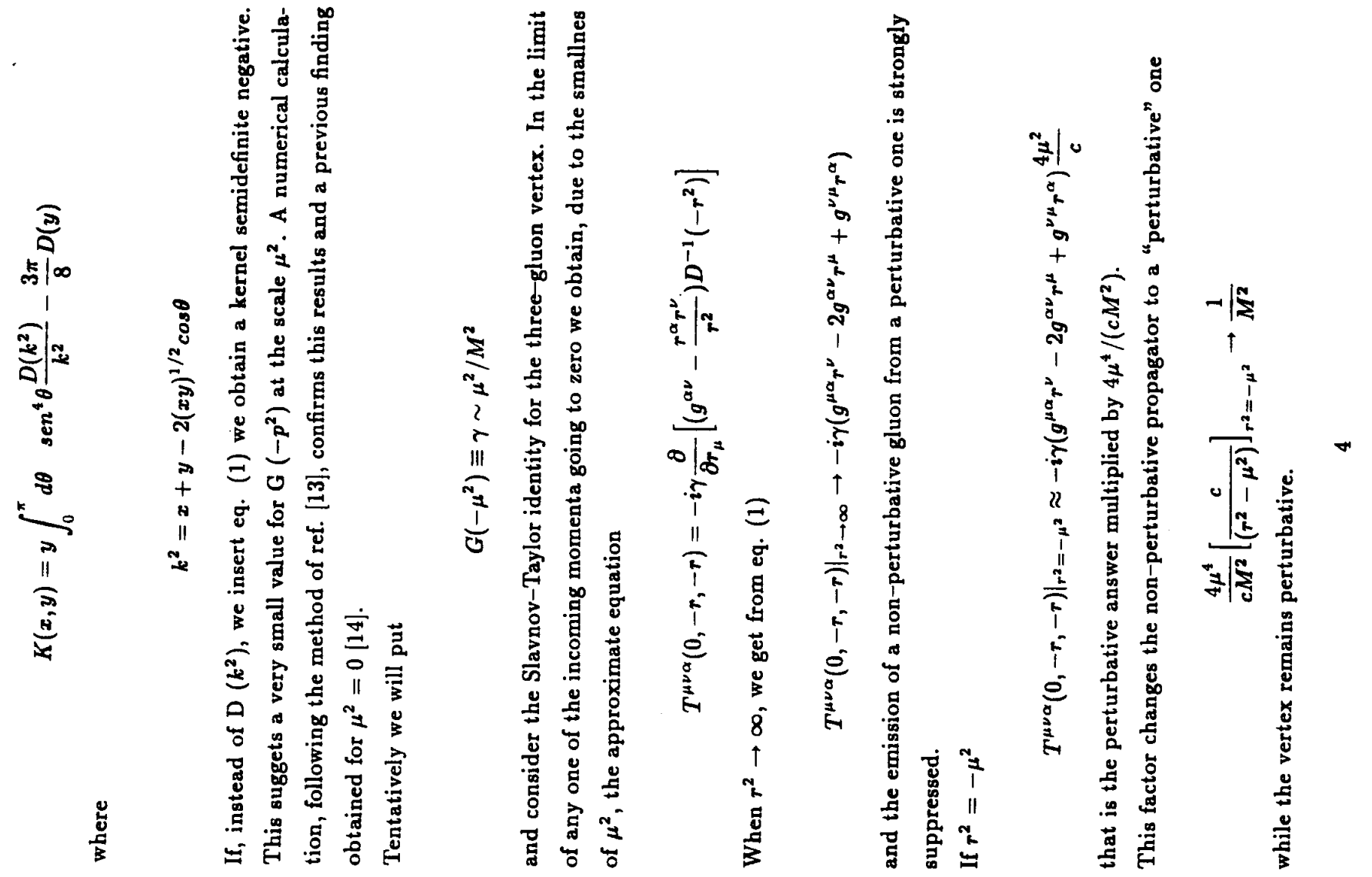




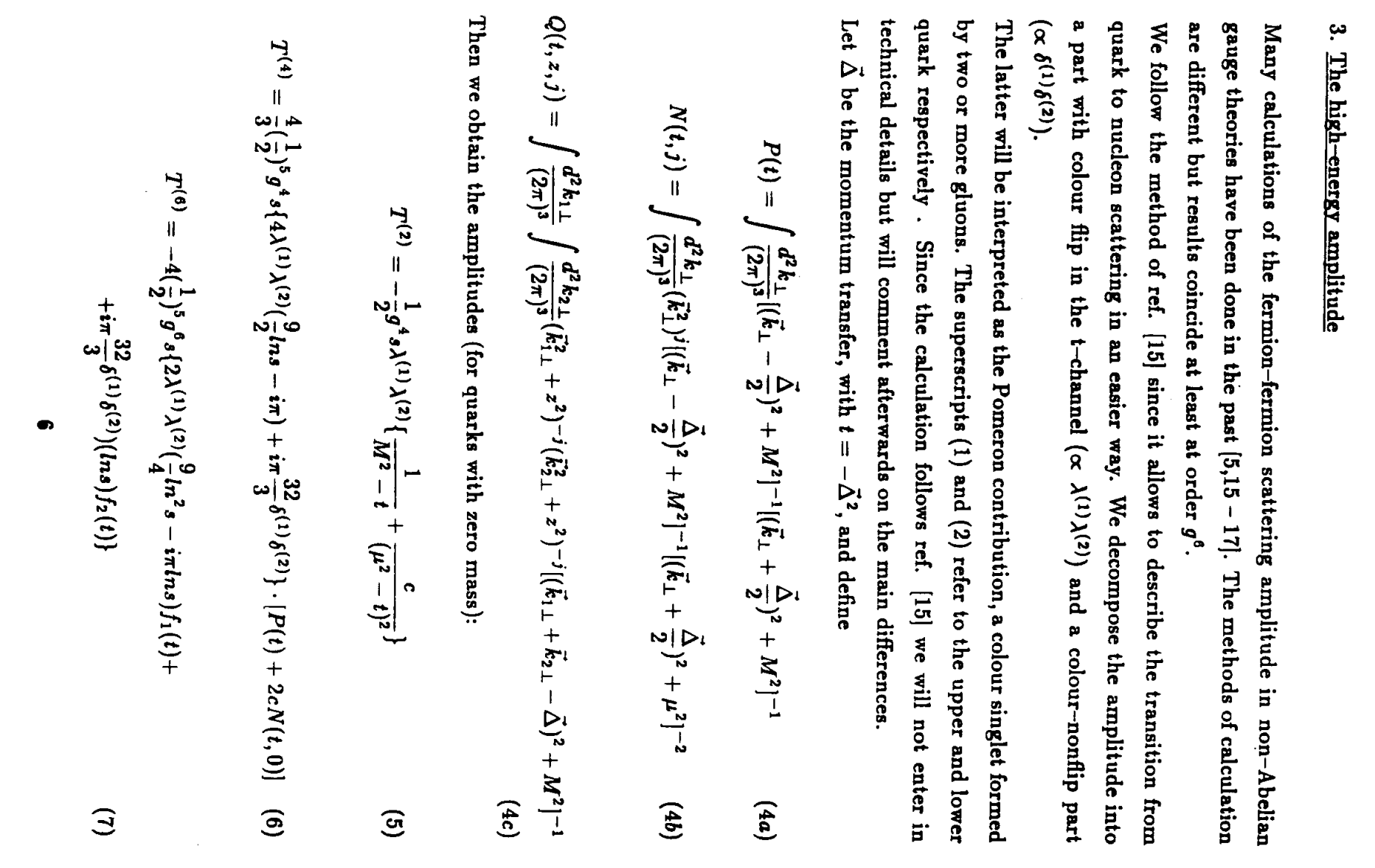

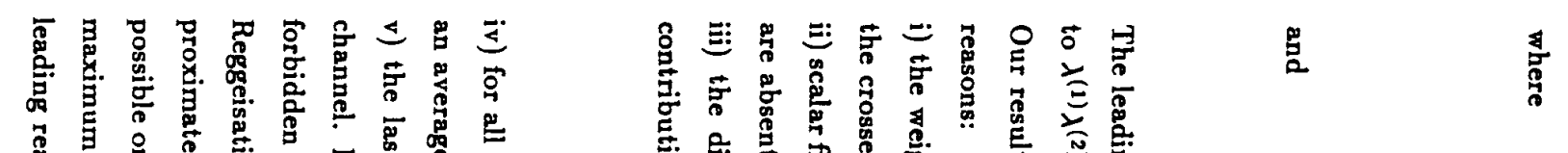

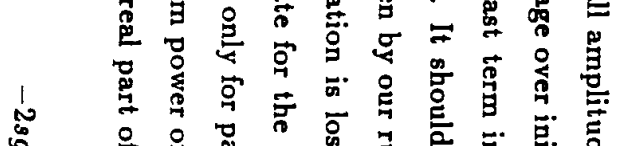

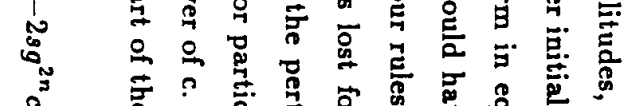

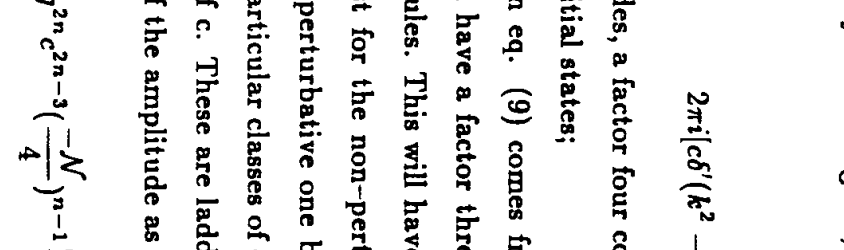

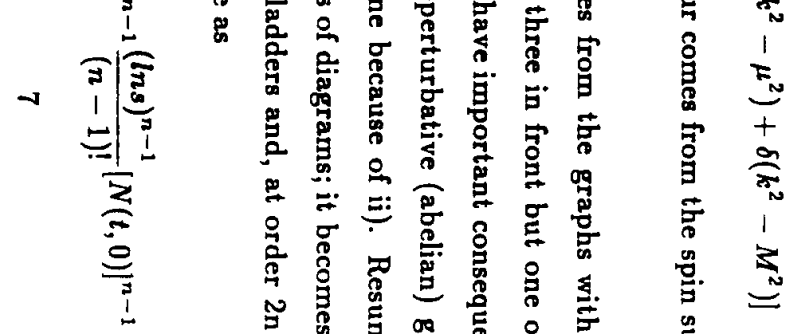

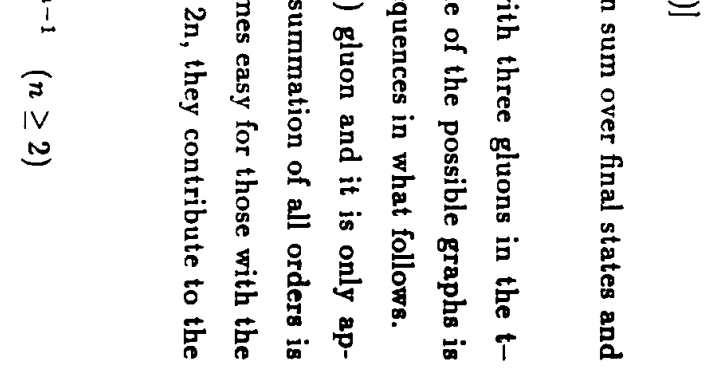

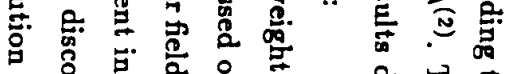

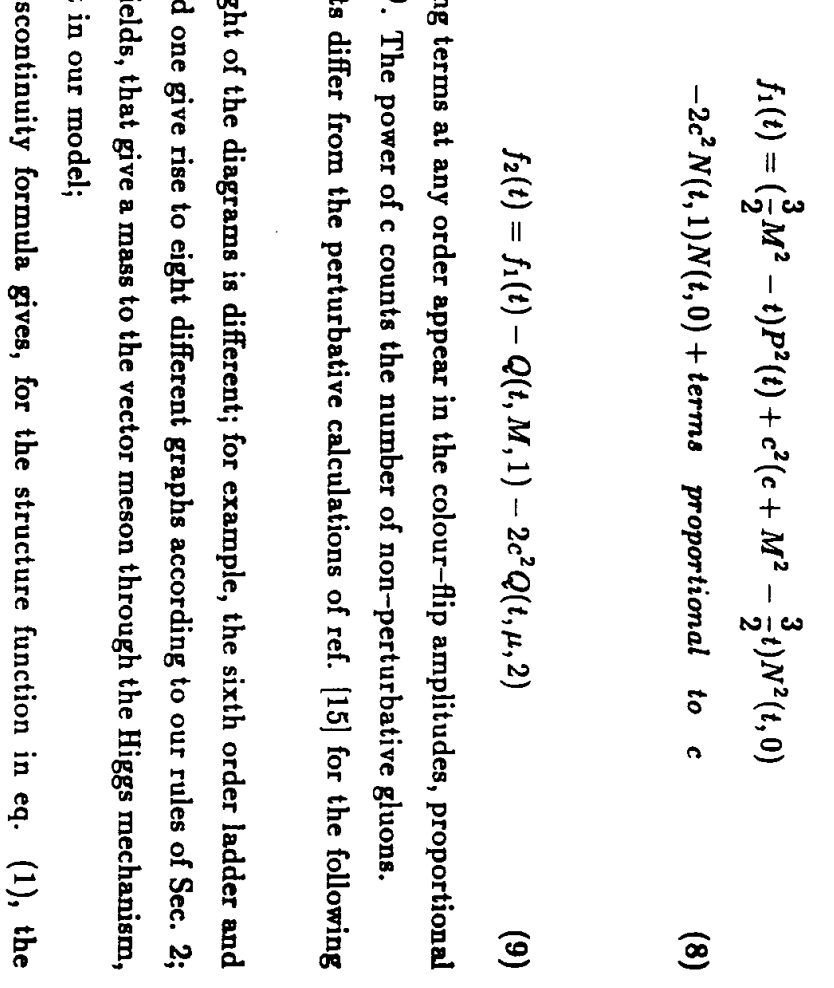



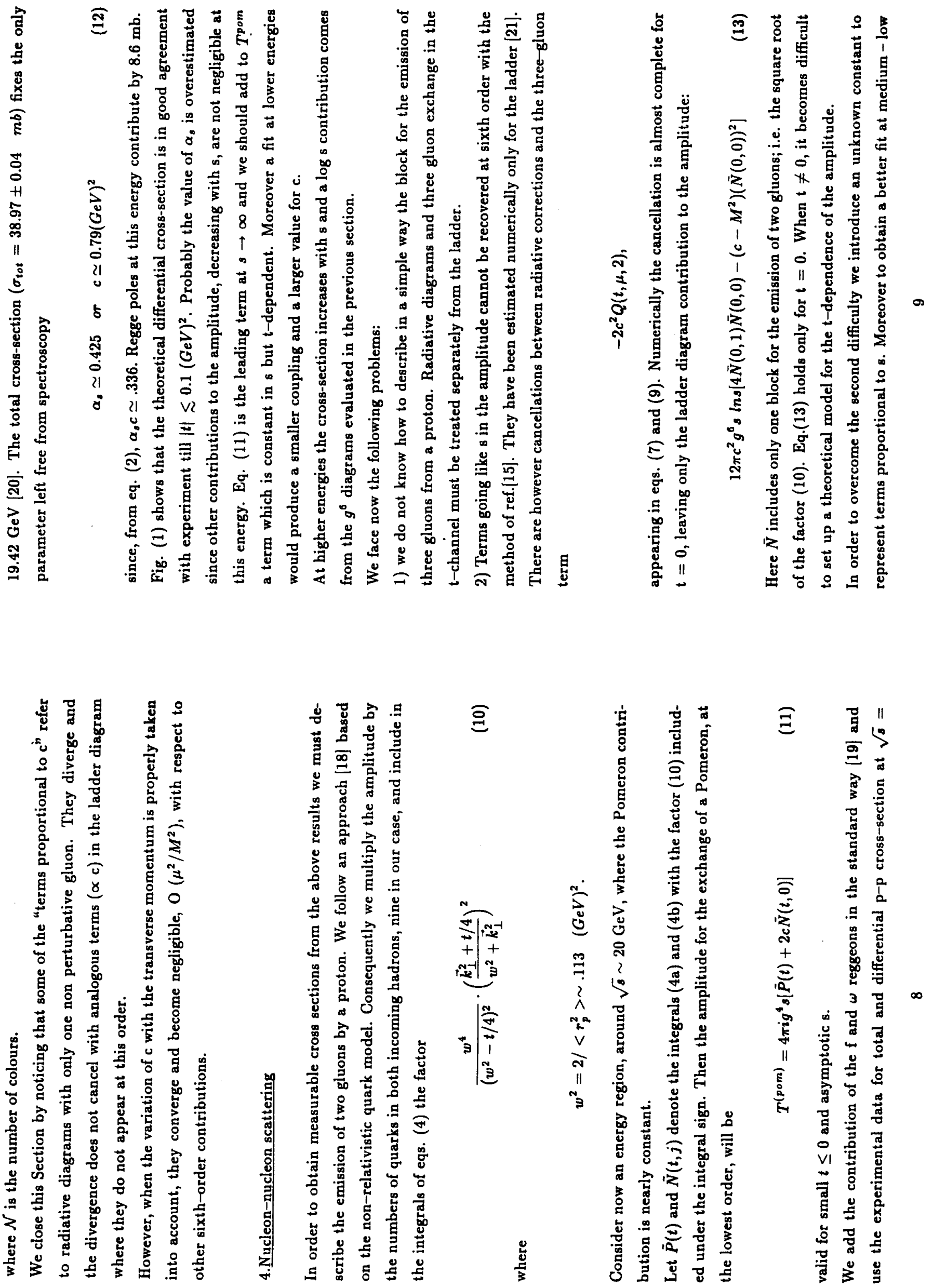

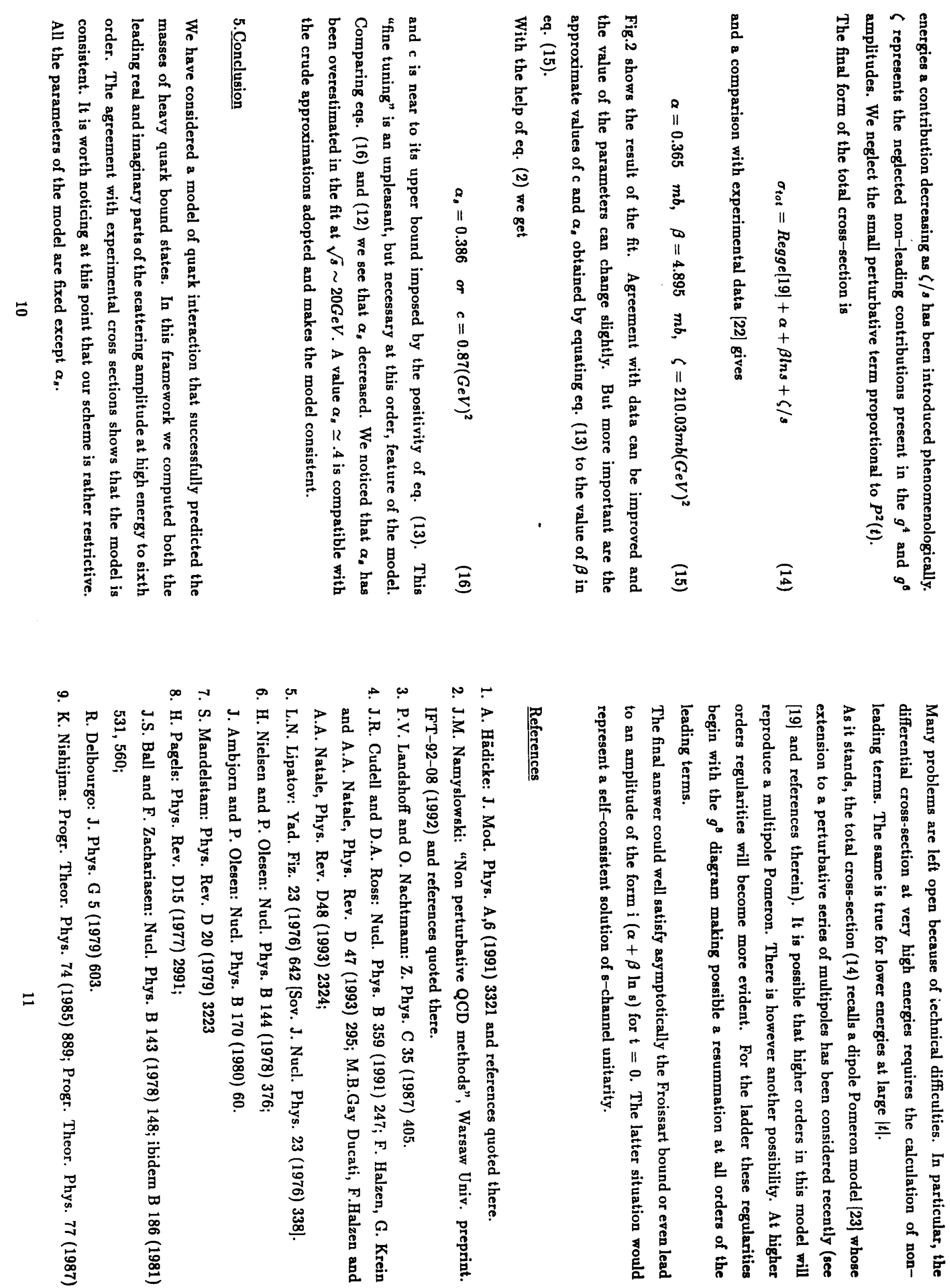

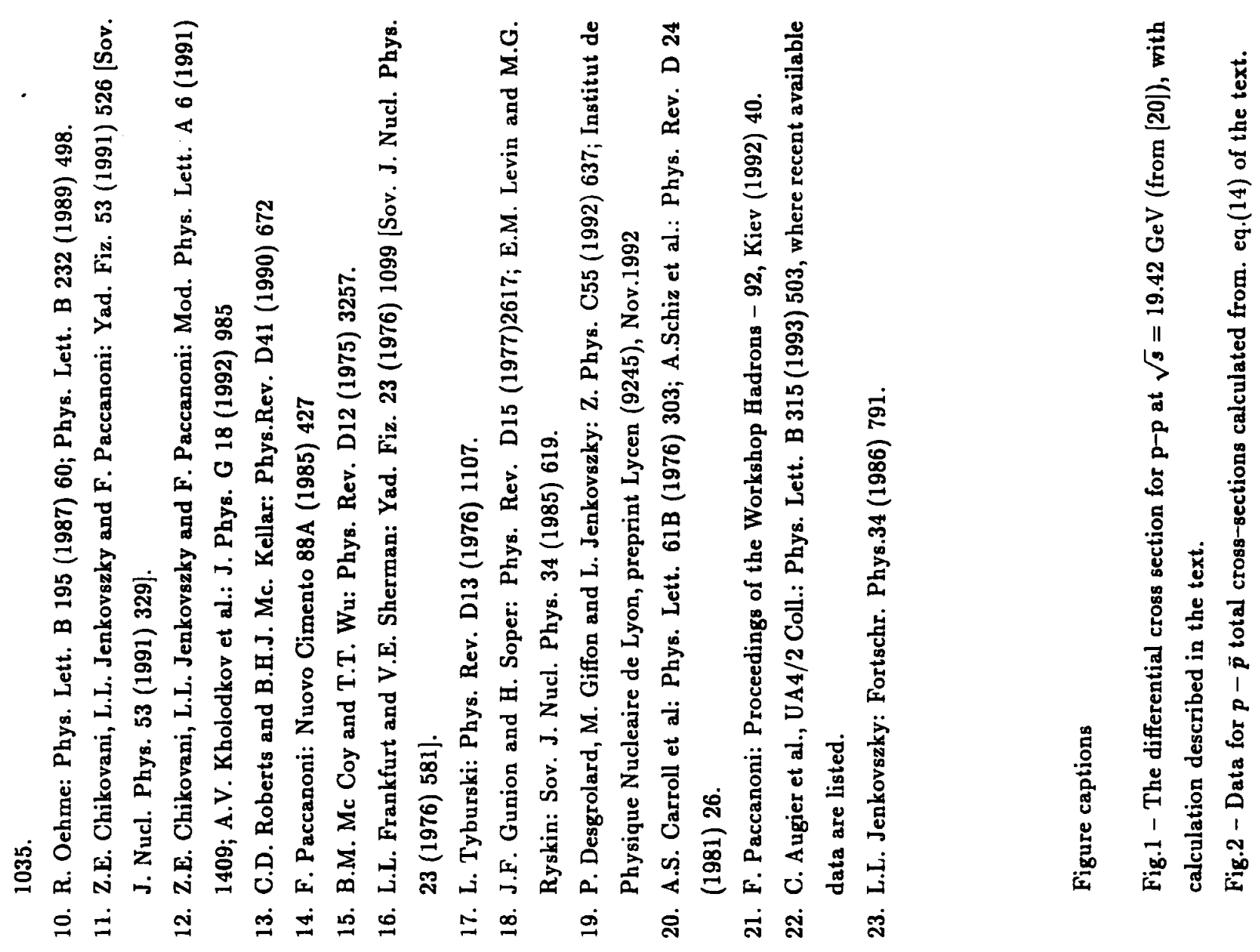


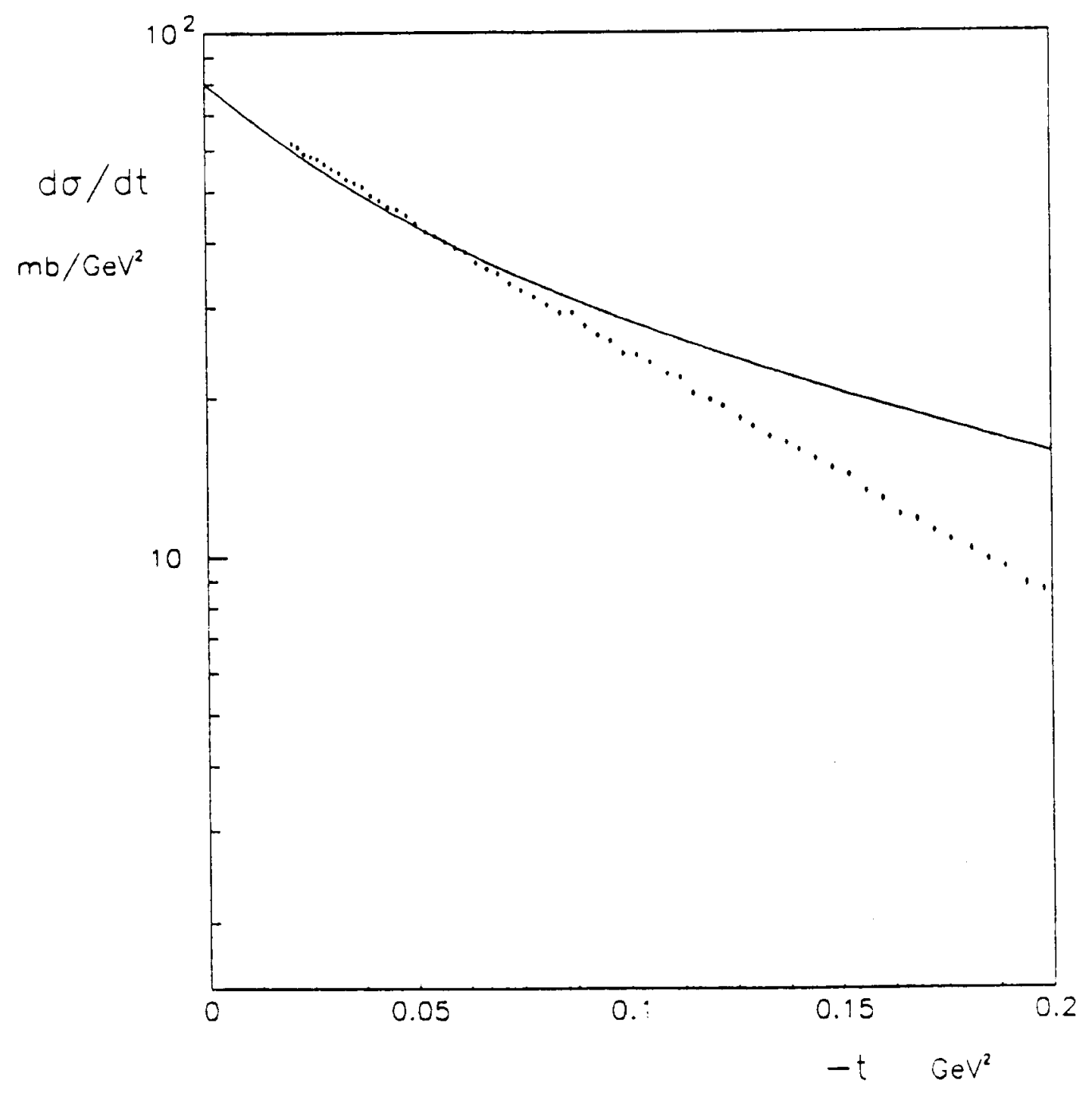

Fig. 1 